\title{
БУДІВНИЦТВО
}

УДК 624.012.45

DOI https://doi.org/10.32838/2663-5941/2021.4/42

\section{Азізов Т.Н.}

Уманський державний педагогічний університет імені Павла Тичини

Срібняк Н.М.

Сумський національний аграрний університет

Циганенко Л.А.

Сумський національний аграрний університет

\section{ВИЗНАЧЕННЯ КРУТИЛЬНОЇ ЖОРСТКОСТІ ЗАЛІЗОБЕТОННОГО ЕЛЕМЕНТА В НОРМАЛЬНІЙ ТРІЩИНІ}

У статті показано, що зміна крутильної жорсткості залізобетонних елементів у результаті утворення нормальних тріщин не враховується в жодному нормативному документі. Крім того, у наукових дослідженнях, присвячених жсорсткості при крученні залізобетонних елементів, розглядаються тільки просторові тріщини. Наведено методику визначення зусиль у поздовжній арматурі й стиснутій зоні бетону за дії крутного моменту з урахуванням дії нагельних сил як у горизонтальному, так і вертикальному напрямках. Для визначення зусиль у бетоні й арматурі залізобетонного елемента з нормальною тріщиною розглянуто плоский поворот перерізу відносно иентру кручення. Показано, щзо крутильна жорсткість залізобетонного елемента з нормальною тріщиною складається з декількох складників. Це жорсткість чистого кручення стиснутої зони бетону й арматурних стержнів, жорсткість у результаті зсуву стиснутої зони бетону й арматурних стержнів у горизонтальному та вертикальному напрямках. Зсув відбувається в результаті повороту всього перерізу відносно иентру кручення. При визначенні жорсткості від зсуву арматури в результаті повороту перерізу щодо иентру жорсткостей ураховується згин арматури, а також зминання бетону під арматурним стержнем. Показано, щчо при малій висоті стиснутої зони бетону нагельні сили в арматурі, визначені за запропонованою методикою, практично повністю збігаються із силами, визначеними в програмі Ліра з використанням об 'ємних скінчених елементів. При збільшенні висоти стиснутої зони бетону похибка зростає. Однак, так як крутильна жсрсткість елемента зменшується практично лінійно зі збільшенням висоти нормальної тріщини, запропоновано визначати ї̈ з малою висотою стиснутої зони за запропонованою методикою. Далі запропоновано визначити жорсткість елемента без тріщин. Усі проміжні значення для різних висот тріщини запропоновано визначати виходячи з лінійного закону між максимальною і мінімальною жорсткостями.

Ключові слова: кручення, нормальна тріщина, нагельна сила, крутильна жорсткість, залізобетонний елемент, арматура.

Постановка проблеми. Відомо, що перерозподіл зусиль у статично невизначених системах, що деформуються просторово (перекриття, мостові споруди тощо), зусилля між окремими елементами перерозподіляються [1; 4]. Цей перерозподіл залежить від співвідношення крутильних і згинальних жорсткостей окремих елементів системи $[1 ; 3 ; 7]$. У залізобетонних системах на згинальну і крутильну жорсткості істотно впливають різні тріщини $[6 ; 8]$. Зміну згинальних жорсткостей у результаті утворення нормальних тріщин можна враховувати різними способами, у тому числі точними $[5 ; 6 ; 8 ; 12]$.

Аналіз останніх досліджень i публікацій. Що ж стосується зміни крутильних жорсткостей, то вітчизняні норми [8] не містять рекомендацій щодо їх визначення. У європейських та американських нормах $[18 ; 21]$, а також у наукових публікаціях $[9-11 ; 19 ; 20]$ містяться рекомендації, що стосуються міцності й деформативності залізобетонних елементів 3 просторовими тріщинами. Однак при експлуатації великого класу 
конструкцій (плити перекриття, мостові балки тощо) 3'являються тільки нормальні й похилі тріщини, які суттєво змінюють не тільки згинальну, а й крутильну жорсткості [2; 17]. Питання дослідження крутильних жорсткостей за наявності в залізобетонних елементах тільки нормальних тріщин практично не розглянуто в літературі. Цьому питанню присвячені роботи автора статті $[2 ; 16 ; 17]$. У цих роботах показано, що одним із основних завдань із визначення крутильної жорсткості залізобетонного елемента є задача визначення нагельної сили в поздовжній арматурі в місці наявності нормальної тріщини. Після визначення нагельної сили задача обчислення крутильної жорсткості елемента 3 нормальною тріщиною вирішується просто.

У роботі [13] запропоновано спосіб визначення крутильної жорсткості елемента 3 нормальними тріщинами. Однак у цій роботі не врахована робота стиснутої зони бетону на зсув, що $є$ істотною похибкою. У роботі [15] усунуто цей недолік і запропоновано спосіб визначення нагельної сили безпосередньо з розгляду деформацій в тріщині. У цій праці як приклад розглянуто елемент 3 однією поздовжньою арматурою. На практиці частіше зустрічаються випадки, коли залізобетонний елемент армується декількома стержнями поздовжньої арматури.

Постановка завдання. У зв'язку з вищесказаним метою статті $€$ розвиток методу, запропонованого в роботі [15], для визначення нагельної сили в поздовжній арматурі $з$ урахуванням зсуву не тільки бетону, а й арматури у двох напрямках.

Виклад основного матеріалу. Нехай є залізобетонний елемент із нормальною тріщиною, армований двома стрижнями арматури. Для визначення нагельних сил у поздовжній арматурі розглянемо деформований стан безпосередньо в нормальній тріщині (рис. 1). На рис. 1 заштрихована частина означає зону бетону без тріщин. Так як нормальні тріщини утворюються в результаті дії згинальних моментів, ця зона є стиснутою зоною бетону. Тому в подальшому ми будемо оперувати цим визначенням.

Для розрахунку застосуємо підхід, описаний у роботі [15], для чого розглянемо плоский поворот усього перерізу відносно центру кручення О. При цьому, як і в праці [15], розглянемо елемент з одиничною товщиною (розмір у напрямку осі Y на рис. 1 дорівнює одиниці). Тому й кут повороту перерізу $\Theta$ буде відносним кутом закручування.

3 причини симетрії перерізу в напрямку осі
$\mathrm{X}$ центр жорсткостей $\mathrm{O}$ знаходиться в середині ширини перерізу. У напрямку осі Z положення центру жорсткостей $\mathrm{O}$ (центру кручення) визначиться за відомою формулою [2] для визначення центра ваги перерізу з урахуванням приведення модуля зсуву арматури до модуля зсуву бетону.

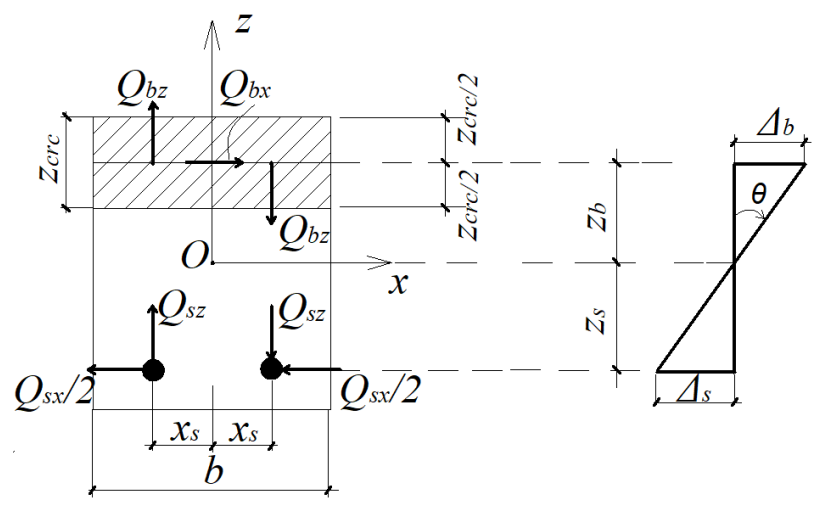

Рис. 1. Схема зусиль (а) і повороту (б) в перерізі 3 тріщиною

На рис. 1, б через $\Delta_{\mathrm{b}}$ позначено переміщення в бетонної частини перерізу на рівні центра ваги цієї частини; через $\Delta_{\mathrm{s}}$ - переміщення на рівні центра ваги арматури. Якщо задано значення відносного кута повороту $\Theta$, то (див. рис. 1) $\Delta_{\mathrm{b}}=\Theta \cdot Z_{\mathrm{b}}$; $\Delta_{\mathrm{s}}=\Theta \cdot \mathrm{Z}_{\mathrm{s}}$.

При повороті перерізу відносно центру жорсткостей зовнішній крутний момент $\mathrm{M}$ сприймається за рахунок опору чистому крученню $\mathrm{M}_{\mathrm{s}, \mathrm{b}}$ та опору зсуву при повороті всього перерізу $\mathrm{M}_{\omega}$. Причому цей момент складається 3 моменту сил $\mathrm{Q}_{\mathrm{sx}}$ та $\mathrm{Q}_{\mathrm{bx}}$ відносно точки $\mathrm{O}$ й діючих у горизонтальному напрямку, а також моменту сил $\mathrm{Q}_{\mathrm{bz}}$ та $\mathrm{Q}_{\mathrm{sz}}$ відносно тієї ж точки. На рис. 1 через $\mathrm{Q}_{\mathrm{bz}}$ позначені рівнодіючі вертикальних сил зсуву ліворуч і праворуч від осі Z.

Момент, що сприймається за рахунок чистого кручення, визначається за відомою формулою опору матеріалів [14]:

$$
M_{s, b}=\theta\left(G J_{b}+2 \cdot G J_{s}\right),
$$

де $G J_{b}$ - крутильна жорсткість бетонного прямокутника зі сторонами $Z_{c r c}$ та $b$ відносно його центра ваги; $G J_{s}$ - крутильна жорсткість одного арматурного стержня відносно його центра ваги.

Крутний момент від сил $\mathrm{Q}_{\mathrm{bx}}$ та $\mathrm{Q}_{\mathrm{sx}}$ дорівнює: $\mathrm{M}_{\mathrm{Qbx}}=\left(\mathrm{Q}_{\mathrm{bx}}=\mathrm{Q}_{\mathrm{sx}}\right) \cdot\left(\mathrm{Z}_{\mathrm{s}}+\mathrm{Z}_{\mathrm{b}}\right)$. Очевидно, що 3 умови рівноваги на ось $\mathrm{X}$ виконується рівність $\mathrm{Q}_{\mathrm{bx}}=\mathrm{Q}_{\mathrm{sx}}$.

Для визначення крутного моменту від зсуву у вертикальному напрямку розіб'ємо стиснуту зону елемента по ширині на деяке число $2 \cdot n+1$ прямокутних елементів (рис. 2). 


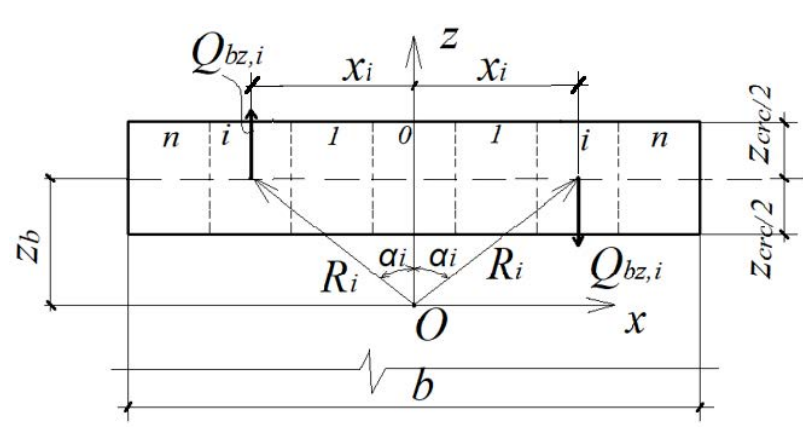

Рис. 2. Схема поділу стиснутої зоні бетону по ширині елемента

Центр ваги і-того елемента знаходиться на відстані $\mathrm{R}_{\mathrm{i}}$ від центру ваги $\mathrm{O}$ всього перерізу. Його положення визначається радіус-вектором $\mathrm{R}_{\mathrm{i}} 3$ кутом нахилу до вертикальної осі $\alpha_{i}$ (див. рис. 2).

При повороті прямокутника шириною $\mathrm{b}$ i висотою $Z_{\text {сrс }}$ У складі всього перерізу елемента 3 тріщиною на деякий кут $\Theta$, вертикальні сили зсуву $\mathrm{Q}_{\mathrm{bz}, \mathrm{i}}$ в кожному i-тому елементі будуть залежати від радіус-вектора $\mathrm{R}_{\mathrm{i}}$ й кута повороту $\alpha_{\mathrm{i}}[15]$.

На рис. 3 наведена схема до визначення повного переміщення $\Delta$ центру ваги і-того елемента при повороті всього перерізу відносно центра кручення на кут $\Theta$, а також складників $\Delta_{\mathrm{x}}$ i $\Delta_{z}$ цього переміщення.

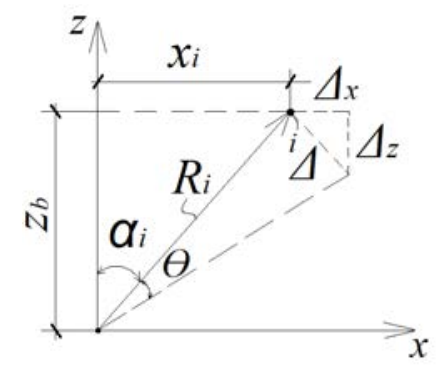

Рис. 3. Схема до визначення переміщень і-того елемента від повороту відносно центра кручення на кут $\Theta$

Повне переміщення $\Delta$ елемента при повороті на кут $\Theta$ дорівнює (див. рис. 3):

$$
\Delta=\theta \cdot R_{i}
$$

Горизонтальна $\Delta_{\mathrm{x}}$ i вертикальна $\Delta_{\mathrm{z}}$ складника 3 урахуванням виразу (2) та рис. 3 визначаться за формулами:

$$
\begin{aligned}
\Delta_{x} & =\theta \cdot R_{i} \cos \alpha_{i}, \\
\Delta_{z} & =\theta \cdot R_{i} \sin \alpha_{i}
\end{aligned}
$$

Кут $\alpha_{\mathrm{i}}$ визначається за рис. 2 та 3 з геометричних міркувань.

Розподіл по ширині перетину виконано за такою схемою (див. рис. 2). Центр ваги нульового елемента знаходиться на осі Z. Елементи $\mathrm{i}=1$...n знаходяться симетрично справа i зліва. Це пов'язано з фактом, що сили $\mathrm{Q}_{z, \mathrm{i}}$ діють симетрично, але в протилежних напрямках.

3 рис. 3 можна бачити, що чим далі від осі Z знаходиться i-й елемент (чим більше відстань $\mathrm{X}_{\mathrm{i}}$ ), тим більше вертикальний складник $\Delta_{z}$ повного переміщення $\Delta$ від повороту перерізу на кут $\Theta \mathrm{i}$, відповідно, тим більше вертикальний складник $\mathrm{Q}_{\mathrm{z}, \mathrm{i}}$ зсуву стиснутої зони бетону.

Водночас зсув $\Delta_{\mathrm{x}}$ в горизонтальному напрямку i $\Delta_{z}$ у вертикальному напрямку визначаються за формулами опору матеріалів [14]:

$$
\Delta_{x}=Q_{b x, i} /\left(G_{b} A_{b i}\right) ; \quad \Delta_{z}=Q_{b z, i} /\left(G_{b} A_{b, i}\right),
$$

де $\mathrm{A}_{\mathrm{b}, \mathrm{i}}$ - площа малого i-го прямокутника (див. рис. 2).

Підставляючи (5) у (3) та (4), отримаємо вирази для сил $\mathrm{Q}_{\mathrm{bx}, \mathrm{i}}$ та $\mathrm{Q}_{\mathrm{bz}, \mathrm{i}}$ :

$$
\begin{aligned}
Q_{b x, i} & =\theta \cdot G_{b} R_{i} A_{b, i} \cos \alpha_{i}, \\
Q_{b z, i} & =\theta \cdot G_{b} R_{i} A_{b, i} \sin \alpha_{i} .
\end{aligned}
$$

Величина $\mathrm{R}_{\mathrm{i}}$ визначається з рисунка 3 :

$$
R_{i}=Z_{b} / \cos \alpha_{i} .
$$

Момент $M_{\text {๗ }}^{x}$ від зсуву бетонної частини в горизонтальному напрямку в результаті повороту всього перерізу відносно центра кручення $\mathrm{O}$ визначиться за формулою (див. рис. 1):

$$
M_{\omega}^{x}=\sum_{i=0}^{2 \cdot n} Q_{b x, i} Z_{b} .
$$

Підставляючи (8) у (6) для $\mathrm{Q}_{\mathrm{bx}, \mathrm{i}}$ в (9) і ураховуючи, що $\sum^{2 \cdot n} A_{b, i}=A_{c r c}$ (де $\mathrm{A}_{\text {crc }}=\mathrm{Z}_{\text {crc }} \cdot \mathrm{b}$ - площа стиснутої зони), бөримаємо:

$$
M_{\omega}^{x}=\theta \cdot G_{b} A_{c r c} Z_{b}^{2}
$$

Розглянемо тепер момент $M_{\omega}^{z}$, який сприймається за рахунок зсуву стиснутої зони бетону у вертикальному напрямку. Цей момент дорівнює (див. рис. 2):

$$
M_{\omega}^{z}=2 \cdot \sum_{i=1}^{n} Q_{b z, i} X_{i}
$$

Множник 2 у формулі (11) означає, що сили $\mathrm{Q}_{\mathrm{bz,i}}$ створюють момент як зліва від осі Z, так і праворуч (див. рис. 2). Крім того, нульовий елемент (що знаходиться по центру на осі Z) не бере участі в сприйнятті моменту від зсуву у вертикальному напрямку. Тому підсумовування ведеться від одиниці до $\mathrm{n}$.

Підставивши (8) у вираз (7) для $\mathrm{Q}_{\mathrm{bz,i},}$ отримаємо:

$$
Q_{b z, i}=\theta \cdot G_{b} Z_{b} A_{b, i} \operatorname{tg} \alpha_{i}
$$

3 рис. 3 легко бачити:

$$
Z_{b}=X_{i} / \operatorname{tg} \alpha_{i}
$$

Підставляючи у (12) вираз для $Z_{\mathrm{b}}$ за (13), а потім цей вираз для $\mathrm{Q}_{\mathrm{bz,i}}$ в (11) і скорочуючи на $\operatorname{tg} \alpha_{\mathrm{i}}$, отримаємо:

$$
M_{\omega}^{z}=2 \cdot \theta \cdot G_{b} \cdot \sum_{i=1}^{n} A_{b, i} X_{i}^{2}
$$


Для визначення моменту від сил $\mathrm{Q}_{\mathrm{sx}} \mathrm{i} \mathrm{Q}_{\mathrm{sz}}$ в арматурних стержнях при повороті перерізу відносно центру кручення $\mathrm{O}$ на кут $\Theta$ будемо керуватися тими ж міркуваннями, що й при виведенні формул для моменту від зсуву стисненого бетону при повороті перерізу. У результаті момент, що сприймається арматурними стрижнями в результаті їх зсуву і згину, буде дорівнювати:

$$
M_{\omega, s}=2 \cdot G_{s_{-} e k v} k_{\text {nag }} A_{s}\left(Z_{s}^{2}+X_{s}^{2}\right)
$$

При цьому у виразі (15) модуль зсуву арматури прийнятий рівним еквівалентному модулю $\mathrm{G}_{\mathrm{s} \text { ekv. }}$ Еквівалентний модуль зсуву повинен бути прийнятий (причому $\mathrm{G}_{\mathrm{s} \_ \text {ekv }}<\mathrm{G}_{\mathrm{s}}$ ) таким чином, щоб сумарне переміщення від зсуву такого еквівалентного стрижня дорівнювало переміщенню від зсуву і згину реального стрижня на одиничній довжині. Тому величину $\mathrm{G}_{\mathrm{s} \_\mathrm{ekv}}$ неважко визначити за відомими формулами опору матеріалів.

Коефіцієнт $\mathrm{K}_{\text {nag }}$ враховує зминання бетону під арматурним стрижнем, його величина визначається відповідно до рекомендацій, наведених у роботі [2].

Повний момент, що сприймається перерізом у тріщині, буде дорівнювати сумі моментів за (1), (10), (14) i (15):

$$
M=\theta\left(\begin{array}{l}
G J_{b}+2 \cdot G J_{s}+G_{b} A_{c r c} Z_{b}^{2}+2 \cdot G_{b} \cdot \sum_{i=1}^{n} A_{b, i} X_{i}^{2}+ \\
+2 \cdot G_{s_{-} e k v} k_{\text {nag }} A_{s}\left(Z_{s}^{2}++X_{s}^{2}\right)
\end{array}\right)
$$

Відмінність виразу (16) від формули (15), яка наведена в праці [15], полягає в наявності доданка, що враховує момент від зсуву арматури у вертикальному напрямку у зв'язку з наявністю двох стержнів поздовжньої арматури. Модуль зсуву арматури $\mathrm{G}_{\mathrm{s}}$ при визначенні жорсткості iі чистого кручення (другий доданок у формулі 16) приймається рівним реальному модулю зсуву.

Перший і другий складник виразу (16) є жорсткостями чистого кручення відповідної стиснутої зони бетону й арматурних стрижнів. Третій і четвертий складники - жорсткості в результаті зсуву стиснутої зони бетону, відповідно, у горизонтальному й вертикальному напрямках. П'ятий доданок означає жорсткість у результаті зсуву арматурних стержнів у горизонтальному й вертикальному напрямках.

Знаючи частку крутного моменту, що припадає на арматурні стержні, неважко визначити значення нагельних сил в арматурі $\mathrm{Q}_{\text {sx }}$ та $Q_{s z}$.

$$
Q_{s, x}=2 \cdot G_{s, e k v} k_{\text {nag }} A_{s} Z_{s} ; Q_{s, z}=2 \cdot G_{s, e k v} k_{\text {nag }} A_{s} X_{s}
$$

Задача 3 кількома стрижнями поздовжньої арматури вирішується із застосуванням такого ж підходу.
Порівняння розрахунків за запропонованою методикою 3 розрахунками в програмному комплексі Ліра-Сапр із застосуванням об'ємних скінчених елементів показує гарний збіг. При малих величинах $Z_{\text {сrс }}$ (малій висоті стиснутої зони бетону) збіг теоретичних даних із даними чисельного розрахунку практично повний, що говорить про достовірність запропонованої методики. При збільшенні висоти стиснутої зони бетону похибка зростає, однак застосування запропонованої методики може бути цілком виправдано з таких причин. Розрахунки в програмі Ліра із застосуванням об'ємних скінчених елементів показують, що крутильна жорсткість залізобетонного елемента 3 нормальною тріщиною зменшується практично лінійно зі збільшенням висоти нормальної тріщини. Тому можна визначити крутильну жорсткість елемента з малою висотою стиснутої зони $Z_{\text {сrс }}$ за виразом (16), а потім визначити жорсткість елемента без тріщини. Усі проміжні значення для різних висот тріщини легко визначаться з лінійного закону.

Після визначення нагельних сил величину взаємного зсуву берегів нормальної тріщини, а також жорсткості перерізу в нормальній тріщині не важко визначити за формулами, які наведені в праці $[2 ; 16 ; 17]$.

Запропонований підхід неважко поширити й на елементи непрямокутного перерізу. При цьому варто також розглянути плоский поворот відносно центру кручення 3 повною аналогією всіх міркувань, наведених у статті.

Висновки. У статті наведено методику визначення зусиль у поздовжній арматурі і стиснутій зоні бетону з урахуванням їх дії як у горизонтальному, так і вертикальному напрямках. Для визначення зусиль у бетоні й арматурі елемента 3 нормальною тріщиною розглянуто плоский поворот перерізу відносно центру кручення. Зовнішній крутний момент сприймається за рахунок чистого кручення, а також за рахунок зсуву в поздовжній арматурі й бетоні у двох напрямках. Наведено формулу для визначення кожного складника загальної крутильної жорсткості.

При малій висоті стиснутої зони бетону нагельні сили в арматурі, визначені за запропонованою методикою, практично повністю збігаються із силами, визначеними в програмі Ліра 3 використанням об’ємних скінчених елементів. Усі проміжні значення крутильної жорсткості для різних висот тріщини запропоновано визначати, виходячи з лінійного закону між максимальною та мінімальною жорсткостями.

У перспективі передбачається поширення методики на врахування нелінійних властивостей бетону і арматури. 


\section{Список літератури:}

1. Азизов Т.Н. Теория пространственной работы перекрытий. Киев : Науковий світ, 2001. 276 с.

2. Азизов Т.Н., Кочкарев Д.В. Определение нагельной силы в продольной арматуре при кручении железобетонных элементов с нормальными трещинами. Sciences of Europe. 2020. Vol. 1. № 58 (2020). P. $36-40$.

3. Айвазов Р.Л., Лапицкий И.В. Сборное перекрытие, опёртое по контуру и работающее с поперечным распором. Бетон и железобетон. 1991. № 11. С. 7-9.

4. Байков В.Н. Расчёт сборного панельного перекрытия на местную продольную линейно-сосредоточенную нагрузку. Проектирование железобетонных конструкций. Москва : Стройиздат, 1966. 380 с.

5. Бамбура A.М. Аналітичне описання діаграми механічного стану арматури для залізобетонних конструкцій. Будівельні конструкиії : міжвідомчий науково-технічний збірник. Київ : НДІБК, 2003. Вип. 59. C. $131-136$.

6. Бамбура А.М., Барашиков А.Я., Гурківський О.Б. Основні положення розрахунку бетонних та залізобетонних конструкцій по національному нормативному документу (ДБН), що розробляється. Будівельні конструкиії. Київ : НДІБК, 2005. Вип. 62 : у 2 т. Том 1. С. 131-136.

7. Дроздов П.Ф. Конструирование и расчёт несущих систем многоэтажных зданий и их элементов. Москва : Стройиздат, 1977. 223 с.

8. ДСТУ Б В.2.6-156: 2010. Конструкції будинків і споруд Бетонні та залізобетонні конструкції з важкого бетону. Правила проектування. Київ : Міністерство регіонального розвитку та будівництва України, 2010. $166 \mathrm{c}$.

9. Елагин Э.Г. Расчет перемещений железобетонных стержней прямоугольного сечения на стадиях работы с трещинами при совместном кратковременном действии моментов и продольной силы. Строительная механика и расчет сооружений. 1991. № 4. С. 26-31.

10. Карпенко Н.И. Теория деформирования железобетона с трещинами. Москва : Стройиздат, 1976. $208 \mathrm{c}$.

11. Коуэн Г.Дж. Кручение в обычном и предварительно напряженном железобетоне / пер. с англ. Москва : Изд-во литературы по строительству, 1972. 104 с.

12. Кочкарьов Д.В. Нелінійний опір залізобетонних елементів і конструкцій силовим впливам : монографія. Рівне : О. Зень, 2015. 384 с.

13. Красин Н.А. Расчеты крутильной жесткости железобетонных конструкций мостов с учетом влияния трещин : автореф. дисс. ... канд. техн. наук. Ташкент, 1994. 16 с.

14. Феодосьев В.И. Сопротивление материалов. Москва, 1999. 592 с.

15. Azizov T.N. Accounting The Shift of The Compressed Area of Concrete in Two Directions in The Torsion of a Reinforced Concrete Element With Normal Crcks. Sciences of Europe. 2021. Vol. 1. № 73. P. 42-46.

16. Azizov T.N. Determination of Displacement of a Reinforced Concrete Element in a Normal Crack. Sciences of Europe. 2021. Vol. 1. № 62. P. 34-38.

17. Azizov T., Jurkowska N., Kochkarev D. Basis of calculation on torsion for reinforced concrete structures with normal cracks (2019) Proceedings of the fib Symposium 2019: Concrete - Innovations in Materials, Design and Structures. P. 1718-1725.

18. American Concrete Institute (ACI) "Building Code Requirements for Reinforced Concrete," ACI 318-89 and "Commentary." ACI 318R-89. Detroit, 1989. 353 p.

19. Collins M.P., Mitchell D. Shear and Torsion Design of Prestressed and Non-Prestressed Concrete Beams. Journal of the Prestressed Concrete Institute. 1980. Vol. 25. № 4. P. 32-100.

20. Cowan H.J. Torsion of a rectangular elastic isotropic beam reinforced with rectangular helices of another material. Applied Scientific Research, Section A. 1952. Volume 3. Issue 5. P. 344-348.

21. EN 1992: Eurocode 2: Design of concrete structures - Part 1: General rules and rules for buildings. Brussels, 2002. $230 \mathrm{p}$.

\section{Azizov T.N., Sribniak N.M., Tsyhanenko L.A. DETERMINATION OF THE TORSIONAL STIFFNESS OF A REINFORCED CONCRETE ELEMENTS IN A NORMAL CRACK}

It is shown that, as a result of the formation of normal cracks in reinforced concrete elements, the change in the torsional stiffness of these elements is not taken into account in any regulatory document. In addition, in scientific research dedicated to the torsional stiffness of reinforced concrete elements, only spatial cracks are considered. The article presents a method for determining the forces in longitudinal reinforcement and the depth to the neutral axis of concrete under the action of a torque. This takes into account the action of the shifting forces in both the horizontal and vertical directions. It is considered a flat rotation of the section relative to the center of torsion to determine the forces in concrete and reinforcement of a reinforced concrete element with 
a normal crack. It is shown that the torsional stiffness of a reinforced concrete element with a normal crack consists of several components. This is the stiffness of the pure torsion of the compressed zone of concrete and reinforcing bars, the stiffness due to displacement of the compressed zone of concrete and reinforcing bars in the horizontal and vertical directions. The shift occurs as a result of the turn of the entire section relative to the torsion center. In determining the stiffness of a section due to reinforcing bar shear as a result of the section turn relative to the center of stiffness, the bending of the rebar, as well as the crumpling of concrete under the reinforcing bar, are taken into account. It is shown that at a low depth to the neutral axis, the shear forces in the reinforcing bar, determined by the proposed method, almost completely coincide with the forces determined by the Lira software package using volumetric finite elements. The error increases with an increase in the depth to the neutral axis of concrete. However, since the torsional stiffness of an element decreases almost linearly with an increase in the height of a normal crack, in the article it is proposed to determine the torsional stiffness with a low depth to the neutral axis according to the proposed method. Further, it is proposed to determine the stiffness of the element without cracks. It has been proposed that all intermediate values for different crack heights should be defined by the linear relation between maximum and minimum stiffness.

Key words: torsion, normal crack, shear force, torsional stiffness, reinforced concrete element, reinforcement. 